University of Nebraska - Lincoln

DigitalCommons@University of Nebraska - Lincoln

Sociology Department, Faculty Publications

Sociology, Department of

2012

\title{
Correlates of Service Utilization among Homeless Youth
}

Kimberly A. Tyler

University of Nebraska-Lincoln, kim@ktresearch.net

Sarah Akinyemi

Lisa Kort-Butler

University of Nebraska-Lincoln, Ikortbutler2@unl.edu

Follow this and additional works at: https://digitalcommons.unl.edu/sociologyfacpub

Part of the Sociology Commons

Tyler, Kimberly A.; Akinyemi, Sarah; and Kort-Butler, Lisa, "Correlates of Service Utilization among Homeless Youth" (2012). Sociology Department, Faculty Publications. 182.

https://digitalcommons.unl.edu/sociologyfacpub/182

This Article is brought to you for free and open access by the Sociology, Department of at DigitalCommons@University of Nebraska - Lincoln. It has been accepted for inclusion in Sociology Department, Faculty Publications by an authorized administrator of DigitalCommons@University of Nebraska - Lincoln. 
Published in Children and Youth Services Review 34 (2012), pp. 1344-1350; doi:10.1016/j.childyouth.2012.03.010

Copyright (c) 2012 Elsevier Ltd. Used by permission. http://www.elsevier.com/locate/childyouth

Received January 16, 2012; revised March 22, 2012; accepted March 23, 2012; published online March 30, 2012.

\title{
Correlates of service utilization among homeless youth
}

\author{
Kimberly A. Tyler, ${ }^{1}$ Sarah L. Akinyemi, ${ }^{2}$ Lisa A. Kort-Butler ${ }^{1}$ \\ 1. Department of Sociology, University of Nebraska-Lincoln, USA \\ 2. Kenexa, Lincoln, NE, USA \\ Corresponding author - K. Tyler, University of Nebraska-Lincoln, Department of Sociology, 717 Oldfather Hall, Lincoln, NE 68588-0324, \\ United States; tel 402 472-6073, fax 402 472-6070, email kim@ktresearch.net
}

\begin{abstract}
Though few studies exist on service utilization among homeless youth in the U.S., services are important because without them, many of these young people may resort to delinquent strategies in order to meet their daily survival needs. The current study examines frequency and correlates of service utilization (i.e., shelters, food programs, street outreach, counseling, STI and HIV testing) among a sample of 249 homeless youth ages 14 to 21 . Multivariate analysis revealed significant differences in service usage by sex, age, and sexual orientation. Experiencing family physical and/or sexual abuse, being kicked out of the family home, spending more nights per week sleeping on the street, and having ever stayed in a group home facility were significant correlates of homeless youths' service usage.
\end{abstract}

Keywords: Service utilization, Family histories, Homeless youth

\section{Introduction}

Although the exact number of youth who run away from home each year is unknown, it is estimated that as many as 2.8 million runaway and homeless youth live on the streets of America everyday (National Runaway Switchboard, 2001). Many of these young people run from abusive and neglectful families (Tyler \& Cauce, 2002) or are forced by parents or guardians to leave their home due to family conflict, illegal behaviors (Whitbeck \& Hoyt, 1999) or due to their sexual orientation (Cochran, Stewart, Ginzler, \& Cauce, 2002). Once on the street, some homeless young people resort to dangerous and/ or illegal activities such as trading sex or selling drugs (Allen et al., 1994; Kipke, Unger, Palmer, Iverson, \& O'Connor, 1998; Rotheram- Borus et al., 1992; Tyler, Hoyt, \& Whitbeck, 2000) because they cannot meet basic survival needs (e.g., food, clothing, and shelter).

Though services such as shelter, food programs, and counseling may be available, numerous barriers to accessing such services exist for homeless youth. These include confidentiality concerns, inability to afford services or lack of health insurance, mistrust, and previous negative experiences with a staff member (Geber, 1997; Solorio, Milburn, Andersen, Trifskin, \& Rodrigues, 2006). Despite these obstacles, many homeless youth still access health-related services such as testing for sexually transmitted infections (STIs) and human immunodeficiency virus (HIV) (Goodman \& Berecochea, 1994; Johnson De Rosa, Montgomery, Hyde, Iverson, \& Kipke, 2001; Solorio, Milburn, Andersen, Trifskin, \& Gelberg, 2006).

Additionally, very little research has examined the characteristics or behaviors of homeless youth that are associated with service usage. This is significant because knowing this information may allow service providers to more effec- tively target homeless youth. Moreover, learning more about the characteristics of youth who do not utilize services is also important, because these individuals may be the ones who are most at risk for engaging in dangerous and illegal activities such as trading sex and selling drugs in order to meet their survival needs. As such, the purpose of this paper is to examine what characteristics of homeless youth are associated with different service usage including shelters, food programs, street outreach, counseling, and STI and HIV testing.

\section{Literature review}

\subsection{Service utilization}

Existing research reveals that homeless youth utilize a variety of services such as drop-in centers, food programs, and street outreach in order to meet their immediate needs. For example, Johnson De Rosa et al. (1999) found that in Hollywood, California, 78\% of homeless youth used drop-in centers and $40 \%$ used shelters. Pergamit and Ernst (2010) also found that drop-in centers were utilized most frequently (58\%) within their sample of homeless youth, followed by food programs (54\%), street outreach (41\%), and counseling (40\%). Approximately $33 \%$ of respondents had used shelter services, and the majority of study youth reported learning about general services via their friends (Pergamit \& Ernst, 2010). Carlson, Sugano,Millstein, and Auerswald (2006) found that among their sample of homeless youth, $99 \%$ of respondents had accessed at least one of the following services within the past three months: shelters, outreach, medical, and/or drug-treatment. The rates of usage, however,were found to vary: $50 \%$ of youth accessed medical services while only $7 \%$ reported using shelters (Carlson et al., 2006). 


\subsection{Characteristics associated with service utilization}

Although a few studies explore service usage among homeless youth, there is a paucity of research that examines the correlates of service utilization. Studies that have looked at this association have found that gender, race, and previous shelter stay are significant correlates. Berdahl, Hoyt, and Whitbeck (2005) found that females and ever having stayed at a shelter were significantly associated with counseling/mental health services. Females were also more likely to have accessed medical services compared to males (Johnson De Rosa et al., 1999; Klein et al., 2000) whereas racial minority homeless youth have been found to utilize shelters more frequently compared to their White counterparts (Johnson De Rosa et al., 1999).

In addition to demographic characteristics, Berdahl and colleagues found that experiencing caretaker abuse was associated with seeing a mental health professional after running away from home, while caretaker rejection and the number of family transitions (e.g., change in family structure, geographic moves) were both associated with mental health counseling services prior to leaving home (Berdahl et al., 2005). Although needs for mental health services are often high due to the family abuse and conflict that many homeless youth experience (Tyler \& Cauce, 2002; Whitbeck \& Hoyt, 1999), levels of usage tend to be low among this high-risk population.

Research has consistently shown that homeless youth have high rates of risky sexual behavior including ever having traded sex and inconsistent condom use (Goodman \& Berecochea, 1994; Kipke et al., 1998; Rotheram-Borus et al., 1992; Tyler et al., 2000), which increases their risk for STIs and HIV. Factors associated with STI testing include older age, amphetamine usage, and being a gay or bisexual male or heterosexual female (Solorio, Milburn, Weiss, \& Batterham, 2006; Tyler \& Melander, 2010). Positive correlates of HIV testing include being older, female, sexually active for more than five years, homeless for more than one year, and having a history of an STI/STD, using injection drugs, engaging in survival sex, or knowing someone with HIV (Goodman \& Berecochea, 1994; Johnson De Rosa et al., 2001; Tyler \& Melander, 2010). Those who seek HIV testing tend to be those who are at highest risk for contracting the disease (Goodman \& Berecochea, 1994; Johnson De Rosa et al., 2001). In sum, various substance use and sexual risk taking have been associated with both STI and HIV testing.

\subsection{Current study}

There is a scarcity of research that has examined correlates of general service usage (though more research has examined STI and HIV testing); therefore, hypotheses are considered exploratory. Because some research has found counseling services and STI and HIV testing to vary by sex, age, or race (Berdahl et al., 2005; Solorio et al., 2006; Tyler \& Melander, 2010), the current study examines these characteristics as potential correlates of service utilization. Second, because many lesbian, gay, bisexual, and transgender (LGBT) youth are often forced to leave home due to their sexual orientation (Cochran et al., 2002) it is possible that they have higher service usage. Third, because general knowledge or level of education may be important for utilization, the current study also examines youth education. Fourth, youth who run away from home due to abuse or neglect or those who spend more time on the street may be in more precarious situations and thus in further need of immediate services. Finally, youth who have prior experience with the state, through their participation in a group home or the foster care system, may be more familiar with the process of accessing services and as such, may be more likely to utilize services compared to those without such experiences.

\section{Design and methods}

\subsection{Sample}

The data are from the Social Network and Homeless Youth Project, a study designed to examine the effect of social networks characteristics on homeless youths' HIV risk behaviors. A total of 249 homeless youth were interviewed in shelters and on the streets from January 2008 to March 2009 in three Midwestern cities in the United States. The Institutional Review Board (IRB) at the University of Nebraska-Lincoln approved this study. Selection criteria required participants to meet the definition of runaway or homeless and be between the ages of 14 and 21. Runaway refers to youth under age 18 who have spent the previous night away from home without the permission of parents or guardians. Homeless included those who have spent the previous night with a stranger, in a shelter or public place, on the street, in a hotel room, staying with friends (e.g., couch surfing), or other places not intended as their resident domicile.

\subsection{Data collection}

Experienced interviewers who have worked on past homeless youth projects, who have served for several years in agencies and shelters that support at-risk youth, and who were very familiar with local street cultures such as knowing where to locate youth and where they congregate conducted the interviews. All interviewers had completed the Collaborative IRB Training Initiative course for the protection of human subjects in research. Interviewers approached shelter residents and located other eligible respondents in areas of the cities where homeless youth congregate. They varied the times of the day on both weekdays and weekends that they went to these locations. This sampling protocol was conducted repeatedly over the course of 15 months. Prior to participation in the study, interviewers obtained informed consent from respondents and told youth that their responses would remain confidential and that their participation was voluntary. The interviews were typically conducted in shelter conference rooms or quiet corners of fast food restaurants if taking the youth back to the shelter was not feasible because of distance or safety concerns. The interview lasted approximately $45 \mathrm{~min}$ and all participants received $\$ 25$ for their involvement and \$5 for a meal. The response rate was $97 \%$ based on the number of initial contacts.

\subsection{Measures}

\subsubsection{Dependent variables}

Six service utilization variables were used for the current study: shelter use, food programs, counseling, street outreach, STI testing, and HIV testing. Respondents were asked how often they used each of the six services in the last year. Response categories for each question ranged from $0=$ never to $5=$ every day. For the multivariate models, each service variable was dichotomized such that $1=$ used the service at least once in the past year and $0=$ never used that particular service in the past year. This dummy coding of the dependent variables is consistent with previous studies and thus allows for research comparisons (Berdahl et al., 2005; Solorio et al., 2006; Solorio et al., 2006).

\subsubsection{Youth characteristic variables}

Sex was coded $0=$ male and $1=$ female and sexual orientation was coded $0=$ lesbian, gay, bisexual, transgender (LGBT) and $1=$ heterosexual. Respondents' age at the time of the interview ranged from 14 to 21. Race was measured by asking respondents "What race or ethnic origin do you consider yourself to be?" White (not of Hispanic origin), Black or African American, Hispanic or Latino, American Indian or Alaskan native, 
Asian, biracial, or multiracial. Due to lack of significant findings between groups, a dichotomized race variable was used in all analyses $(0=$ non-White and $1=$ White $)$. Youth education was measured by asking respondents "What is the last grade you completed in school?" Responses ranged from $1=$ less than 6 th grade to 12 = have college degree.

\subsubsection{Family background variables}

Child abuse included two questions: "Were you ever physically or sexually abused as a child (under age 18)?" $(0=$ No, $1=$ Yes).

\subsubsection{Youth history variables}

A single item indicator measured whether youth had been kicked out of their home by a parent/caretaker $(0=$ No, $1=$ Yes $)$. Number of times run was a single item measure which asked youth how many times they had run from home. Response categories were collapsed due to skewness into the following: $1=1$ time, $2=2$ times, $3=3$ times, $4=4-5$ times, $5=6-10$ times, $6=11-20$ times, and $7=21$ or more times. Number of nights on the street was measured by asking "On average, how many nights a week do you spend on the street?" Open ended responses were collapsed into $0=0$ nights, $1=1$ night, $2=2$ nights, $3=3$ nights, $4=4$ or more nights to obtain an acceptable level of skewness. Group home and foster care asked, "Have you ever lived in a group home?" and "Have you ever lived in foster care?" ( 0 = No, 1 = Yes).

\subsection{Data analyses}

Frequencies for service utilization are presented first. Next, in order to examine the unique impact of each individual variable with each of the six services, bivariate associations are presented using contingency table analysis for dichotomous variables (as well as their prevalence ratios and 95\% confidence intervals) and student's t-tests for continuous variables. Finally, logistic regression is used (displaying the odds ratios $[\operatorname{Exp}(\mathrm{B})]$ ) in order to adjust for the influence of all other variables. Thus the results show both individual and combined effects.

\section{Results}

\subsection{Sample characteristics}

The sample was comprised of 137 females (55\%) and 112 males (45\%). Ages ranged from 14 to 21 years with a mean of 18.5 years. A total of 44 respondents (17.7\%) identified as LGBT. Approximately one half of the sample was White $(49.4 \%)$, with the remaining respondents self-identifying as Black (23.7\%), Hispanic $(8 \%)$, American Indian or Alaskan native $(4.8 \%)$, Asian $(1.2 \%)$, biracial $(8.8 \%)$, and multiracial $(4 \%)$. About $31 \%$ of the sample had completed 12th grade or earned a General Equivalency Diploma (GED), and almost 7\% had attended at least some college. A majority of youth (55\%) had been physically abused at least once and one-third (33\%) reported that they had been a victim of sexual abuse. Forty-six percent of youth reported having been kicked out of their home. Youth reported running an average of three times; however, almost $15 \%$ of the sample had run 11 times or more. Twelve percent of the sample spent an average of one to two nights per week on the street, but almost $11 \%$ reported spending an average of four or more nights per week on the street. A total of $48 \%$ of youth have ever lived in a group home and $37 \%$ have spent time in foster care.

\subsection{Service utilization frequencies}

Table 1 shows the frequency of service usage in the past year. Noteworthy is that approximately $52 \%$ of homeless youth were tested for STIs and HIV a few times per year. In addition, almost $27 \%$ of youth said they were using shelter daily and $17 \%$ were using some type of food program on a daily basis. Youth also exist on the other end of the continuum whereby $44 \%$ reported never using shelter, $34 \%$ never used food programs, and 57\% reported never using counseling services.

\subsection{Bivariate associations}

Table 2 displays bivariate associations between the dichotomous correlates and ever having used any of the services. As shown in column one, those who experienced physical abuse, had been kicked out, and who had ever lived in a group home were significantly more likely to have used shelter compared to their counterparts. Column two revealed that LGBT youth and those who have experienced sexual abuse were significantly more likely to have ever used food programs compared to heterosexual youth and non-sexually abused individuals. In terms of counseling (column three), all independent variables were significant with the exception of sex and race. Column four (Table 2 continued), revealed that LGBT youth and those who have suffered physical and sexual abuse were significantly more likely to have used street outreach compared to heterosexual youth and those with no abuse experiences. In terms of STI testing (column five), females and LGBT youth were more likely to use STI testing compared to males and heterosexuals. In addition, experiencing sexual abuse and ever having lived in a group home or foster care were also significant correlates of STI testing. Finally, column six shows the results for HIV testing. LGBT youth, sexually abused individuals, those who have been kicked out, and those who ever lived in a group home or foster care were significantly more likely to use HIV testing services compared to their counterparts.

Table 3 displays bivariate associations between continuous correlates and ever having used any of the six services. Results revealed that a greater frequency of running away was associated with shelter usage whereas being older, having higher education, and spending more nights on the street were correlated with food program usage. Counseling services were used by those who ran from home more frequently, whereas street outreach services were utilized by older individuals, those with higher education, and those who spent more nights sleeping on the street. STI testing and HIV testing were significantly associated with older age and higher education, whereas HIV testing was also significantly associated with running from home more frequently.

Table 1. Frequency of service utilization in the past year.

\begin{tabular}{|c|c|c|c|c|c|c|c|c|c|c|c|c|}
\hline & \multicolumn{2}{|c|}{ Never } & \multicolumn{2}{|c|}{$\begin{array}{l}\text { Few times } \\
\text { per year }\end{array}$} & \multicolumn{2}{|c|}{$\begin{array}{l}\text { Once } \\
\text { per month }\end{array}$} & \multicolumn{2}{|c|}{$\begin{array}{l}\text { Few times } \\
\text { per month }\end{array}$} & \multicolumn{2}{|c|}{$\begin{array}{l}1-2 \text { times } \\
\text { per week }\end{array}$} & \multicolumn{2}{|c|}{ Everyday } \\
\hline & $\mathrm{N}$ & $\%$ & $\mathrm{~N}$ & $\%$ & $\mathrm{~N}$ & $\%$ & $\mathrm{~N}$ & $\%$ & $\mathrm{~N}$ & $\%$ & $\mathrm{~N}$ & $\%$ \\
\hline How often do you stay at a shelter? & 110 & $44 \cdot 4$ & 50 & 20.2 & 0 & 0.0 & 9 & 3.6 & 13 & 5.2 & 66 & 26.6 \\
\hline How often do you participate in food programs? & 84 & $33 \cdot 7$ & 28 & 11.2 & 10 & 4.0 & 41 & 16.5 & 43 & $17 \cdot 3$ & 43 & $17 \cdot 3$ \\
\hline How often do you use counseling services? & 143 & $57 \cdot 4$ & 27 & 10.8 & 10 & $4 \cdot 0$ & 29 & 11.6 & 35 & 14.1 & 5 & 2.0 \\
\hline How often do you use street outreach services? & 88 & $35 \cdot 3$ & 38 & $15 \cdot 3$ & 18 & 7.2 & 32 & 12.9 & 43 & $17 \cdot 3$ & 30 & 12 \\
\hline How frequently are you tested for STIs? & 76 & 30.5 & 130 & 52.2 & 33 & $13 \cdot 3$ & 7 & 2.8 & 3 & 1.2 & 0 & 0.0 \\
\hline How frequently are you tested for HIV? & 90 & 36.1 & 129 & 51.8 & 22 & 8.8 & 6 & 2.4 & 2 & 0.8 & 0 & 0.0 \\
\hline
\end{tabular}


Table 2. Bivariate associations between dichotomous correlates and services $(n=249)$.

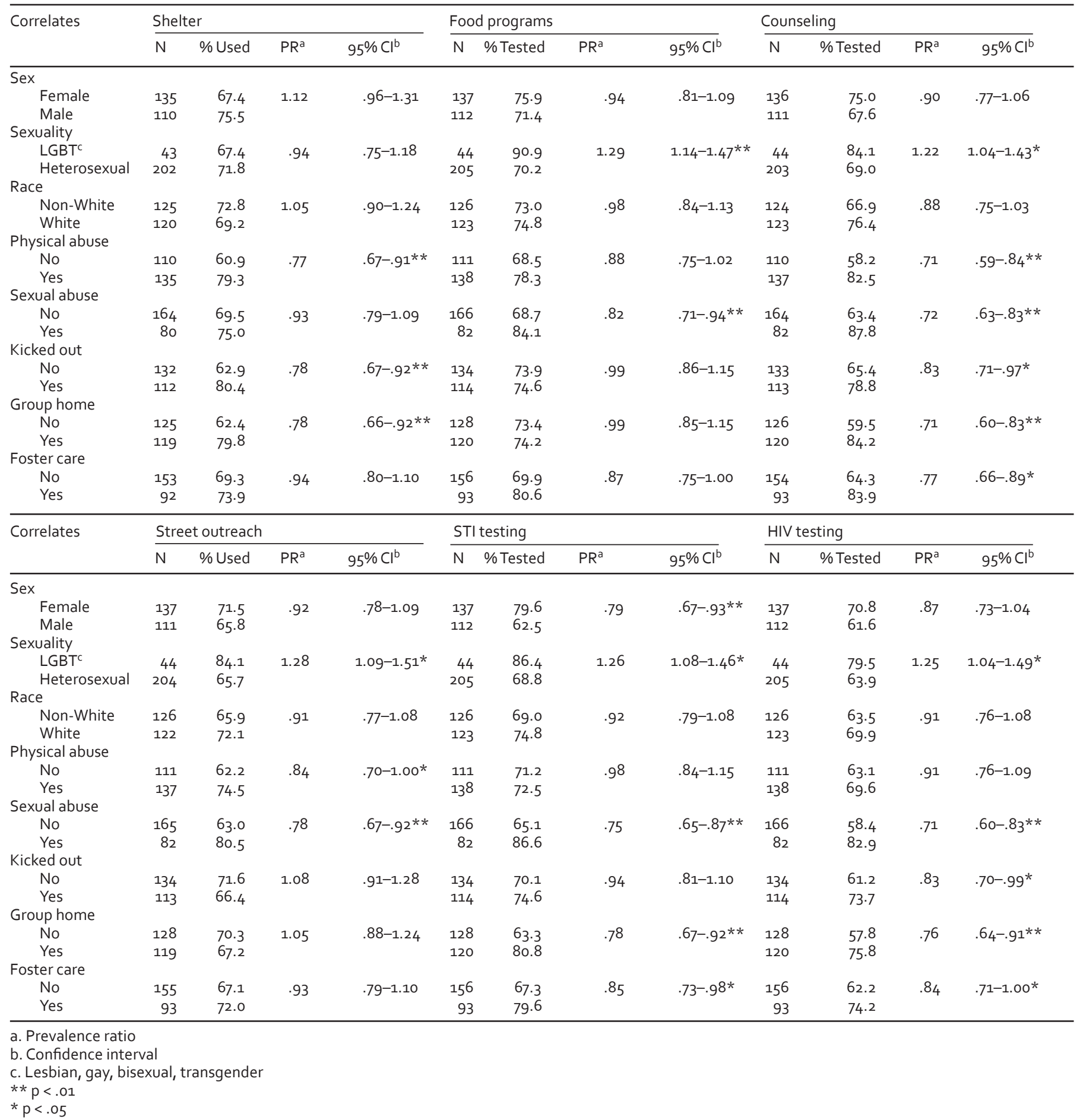

\subsection{Multivariate associations}

Table 4 displays the results from logistic regression. Although numerous variables were associated with various types of service utilization at the bivariate level, when the model was adjusted for the influence of all other variables, some of the previous relationships were reduced to non-significance. In column one, the results revealed that physically abused youth had over two times greater odds of using shelter services compared to those who had not been physically abused $(\operatorname{Exp}(B)=$ 2.09; $p<.05)$. Youth who had ever been kicked out and who had ever stayed in a group home had over two times greater odds of using shelter services $(\operatorname{Exp}(B)=2.06 ; \mathrm{p}<.05$ and $\operatorname{Exp}(B)=2.44 ; p<.01$, respectively).

Column two shows that heterosexual youthwere $71 \%$ less likely to use food programs compared to LGBT youth $(\operatorname{Exp}(B)$ $=.29 ; \mathrm{p}<.05)$. In addition, for every one unit increase in age there was a $37 \%$ increase in the likelihood of having ever used food programs $(\operatorname{Exp}(B)=1.37 ; p<.01)$. Finally, young people who spent more nights sleeping on the street had one and a half times greater odds of using food programs $(\operatorname{Exp}(B)=1.55$; $\mathrm{p}<.05)$.

Column three reveals a positive correlation between counseling usage and group home. That is, homeless youth who 
Table 3. Bivariate associations between continuous correlates and services $(n=249)$.

\begin{tabular}{|c|c|c|c|c|c|c|c|c|c|}
\hline \multirow[t]{2}{*}{ Correlates } & \multicolumn{3}{|l|}{ Shelter } & \multicolumn{3}{|c|}{ Food program } & \multicolumn{3}{|l|}{ Counseling } \\
\hline & Not used & Used & t-test & Not used & Used & t-test & Not used & Used & t-test \\
\hline Age & 18.55 & 18.52 & .124 & 17.74 & 18.82 & $-4 \cdot 248 * *$ & 18.74 & 18.44 & 1.176 \\
\hline Youth education & 7.08 & 6.99 & .366 & 6.60 & 7.19 & $-2.216 *$ & 7.16 & 6.98 & .661 \\
\hline Times run & 2.79 & 3.36 & $-2.143^{*}$ & 2.95 & 3.26 & -1.125 & 2.41 & 3.47 & $-4.082 * *$ \\
\hline Nights/week street & .76 & .81 & -.247 & .25 & .97 & $-3.656 * *$ & .79 & .78 & .008 \\
\hline \multirow[t]{2}{*}{ Correlates } & \multicolumn{3}{|c|}{ Street outreach } & \multicolumn{3}{|l|}{ STI testing } & \multicolumn{3}{|l|}{ HIV testing } \\
\hline & Not used & Used & t-test & Not tested & Tested & t-test & Not tested & Tested & t-test \\
\hline Age & 17.82 & 18.86 & $-4 \cdot 317^{* *}$ & 17.66 & 18.88 & $-4.989 * *$ & 17.81 & 18.90 & $-4.648 * *$ \\
\hline Youth education & 6.61 & 7.22 & $-2.416 *$ & 6.60 & 7.21 & $-2.334^{*}$ & 6.54 & 7.28 & $-3.101 *$ \\
\hline Times run & 3.19 & 3.19 & .029 & 2.86 & $3 \cdot 31$ & -1.693 & 2.69 & 3.43 & $-2.956 *$ \\
\hline Nights/week street & .45 & .94 & $-2.582 *$ & .64 & .84 & -.993 & .64 & .85 & -1.159 \\
\hline
\end{tabular}

$* * p \leq .01 ; * p \leq .05$

have ever stayed in a group home had about two and a half times greater odds of using counseling services $(\operatorname{Exp}(B)=2.50$; $\mathrm{p}<.01)$ compared to those who have never lived in a group home. No other variables in this model reached statistical significance despite the fact that several variables including sexuality, physical and sexual abuse, being kicked out, foster care, and number of times run were significant at the bivariate level.

Street outreach service (column four) was significantly associated with age and being kicked out of home. For every one unit increase in age there was a $35 \%$ increase in the likelihood of using street outreach $(\operatorname{Exp}(B)=1.35 ; \mathrm{p}<.01)$. Additionally, youth who have been kicked out were $54 \%$ less likely, compared to other youth, to use outreach services $(\operatorname{Exp}(B)=.46 ; \mathrm{p}<.05)$. Finally, those who were physically abused $(\operatorname{Exp}(B)=2.03 ; p<.10)$ and those who spent more nights on the street $(\operatorname{Exp}(B)=1.26 ; p<.10)$ had greater odds of using outreach services.

In terms of STI and HIV testing (columns five and six) older individuals and those who have stayed in a group home had greater odds of using these services compared to their counterparts. Additionally, females had almost three times greater odds of having been tested for STIs compared to males $(\operatorname{Exp}(B)$ $=2.75 ; \mathrm{p}<.01)$ whereas sexually abused youth had over two times greater odds of having been tested for HIV $(\operatorname{Exp}(B)=2.28$; $\mathrm{p}<.05)$ compared to their non-sexually abused counterparts.

\section{Discussion}

The purpose of this paper was to examine the frequency and correlates of service utilization including shelters, food programs, counseling, street outreach, and STI and HIV testing among homeless youth. Currently, little is known about general service usage patterns among homeless youth even though this is a vulnerable population that often faces barriers to using services (e.g., confidentiality concerns) but is a group in need of such resources. Failure to reach out to these high-risk youth may result in continued participation in dangerous activities such as selling drugs and trading sex, which may have longterm negative effects. Alternatively, gaining a better understanding of why homeless youth do or do not use services may have a substantial impact on service providers' ability to meet youths' needs before they begin engaging in risky behaviors.

The results of this study reveal that numerous youth take advantage of a variety of services while on the street, but there is also a sizeable group who do not benefit from such services: $36 \%$ and $31 \%$ of youth have not been tested for HIV and STIs, respectively, in the past year. This is significant given that $92 \%$ of respondents have engaged in sexual intercourse and the majority of these have participated in high-risk sexual activities such as inconsistent condom usage, trading sex, and having sexual relations with multiple partners. Some of

Table 4. Logistic regression models for correlates of ever having used services $(n=249)$.

\begin{tabular}{|c|c|c|c|c|c|c|}
\hline Correlates & $\begin{array}{l}\text { Shelter } \\
\operatorname{Exp}(B)\end{array}$ & $\begin{array}{c}\text { Food program } \\
\operatorname{Exp}(B)\end{array}$ & $\begin{array}{c}\text { Counseling } \\
\operatorname{Exp}(B)\end{array}$ & $\begin{array}{l}\text { Street outreach } \\
\operatorname{Exp}(B)\end{array}$ & $\begin{array}{l}\text { STI testing } \\
\operatorname{Exp}(B)\end{array}$ & $\begin{array}{l}\text { HIV testing } \\
\operatorname{Exp}(B)\end{array}$ \\
\hline \multicolumn{7}{|l|}{ Youth characteristics } \\
\hline Female & .831 & 1.193 & 1.210 & 1.357 & $2.747^{* *}$ & 1.469 \\
\hline Heterosexual & 1.297 & $.290 *$ & .447 & .515 & .552 & .623 \\
\hline Age & .987 & $1.369 * *$ & .841 & $1.353^{* *}$ & $1.697 * *$ & $1.471 * *$ \\
\hline White & .671 & .751 & 1.544 & 1.007 & .832 & .815 \\
\hline Youth education & 1.016 & .933 & 1.006 & .963 & .916 & 1.014 \\
\hline \multicolumn{7}{|l|}{ Family background } \\
\hline Physical abuse & $2.090 *$ & 1.314 & 1.809 & $2.033^{+}$ & .545 & .567 \\
\hline Sexual abuse & .796 & 1.308 & 1.839 & 1.769 & 2.000 & $2.277^{*}$ \\
\hline \multicolumn{7}{|l|}{ Youth history } \\
\hline Kicked out & $2.055^{*}$ & .657 & 1.534 & $.456 *$ & 1.327 & 1.682 \\
\hline \# times run & 1.065 & 1.036 & 1.155 & .921 & 1.055 & 1.163 \\
\hline Nights/week on street & .988 & $1.552 *$ & .914 & $1.262+$ & .972 & .905 \\
\hline Group home & $2.439 * *$ & .694 & $2.496 * *$ & .609 & $2.683 * *$ & $2.188 *$ \\
\hline Foster care & .704 & 1.636 & 1.346 & 1.065 & 1.299 & 1.191 \\
\hline Nagelkerke & .15 & .22 & .27 & .20 & .29 & .25 \\
\hline
\end{tabular}

$* * p \leq .01 ; * p \leq .05 ;+p<.10$ 
these high-risk individuals may be STI carriers but are unaware because they have not been recently tested. Additionally, $57 \%$ of youth have not used counseling in the past year. This is also noteworthy given that over half of the sample has experienced physical abuse and one-third has been sexually abused. Such results suggest that many of these young people may not be receiving the necessary services, which may result in negative outcomes such as re-victimization and mental health problems.

In terms of youth characteristics, respondent's sex was associated with only one type of service: STI testing. That is, females had greater odds of being tested for STIs compared to their male counterparts, which is consistent with previous research (Solorio et al., 2006). One reason homeless females are more likely to be tested is that they may actually have higher rates of STIs compared to their male counterparts, as indicated by previous research (Tyler, Whitbeck, Chen, \& Johnson, 2007). Additionally, females may be more likely to be tested because of their higher risk of contracting STIs/STDs, given that they often engage in sexual intercourse with older males who likely have had more lifetime sexual partners and thus greater risk (Athey, 1991). Furthermore, women may have less control when it comes to condom usage during sexual interactions (Bailey, Camlin, \& Ennett, 1998), which also contributes to STI and HIV transmission concerns. Finally, it is probable that females are more likely to be tested because they are twice as likely to use medical services compared to males, often due to their gynecological needs (Johnson De Rosa et al., 1999), and thus when they have an STI it is more likely to be detected.

Very little research exists on LGBT homeless youth and even less is known about their service usage patterns. The bivariate analyses revealed that LGBT youth, compared to heterosexual youth, more often use food programs, counseling, street outreach, and STI and HIV testing. When controlling for other variables, however, sexual orientation was only associated with food programs, such that heterosexual youth had lower odds of using this service compared to LGBT youth. No other significant differences were found between heterosexual youth and LGBT youth indicating that their service usage is similar when controlling for other factors. In contrast, other studies have found that homeless LGBT youth are less likely to use services (Cochran et al., 2002), because they may be worried about stigmatization from staff members or about unfair treatment based on their sexual orientation. More research is needed with LGBT homeless youth to understand their usage patterns and barriers to seeking services.

The final youth characteristic associated with service usage was age: older individuals had greater odds of using food programs and street outreach. It is possible that younger aged respondents are less likely to use these particular services because disclosing their age may lead the agency to notify their parents, the state/social worker, or police (Geber, 1997; Solorio et al., 2006). Related to this, many youth do not want to be returned to homes in which they fled because of abuse or conflict (Tyler \& Cauce, 2002). Furthermore, younger aged respondents may have the option of staying with friends or relatives and thus may not have the same level of need for services compared to older homeless youth whose living situations may be precarious. Finally, it is possible that older youth have more extensive street networks and thus are more knowledgeable about how to access these resources (Pergamit \& Ernst, 2010).

In the current study, older youth also had greater odds of being tested for both STIs and HIV, which is consistent with previous research (Goodman \& Berecochea, 1994; Solorio et al., 2006). One possible explanation for the higher rate of testing among older homeless youth is that they are more knowledgeable about how STIs and HIV are contracted, including their associations with high-risk sexual behaviors. Although numerous homeless young people participate in risky behaviors (Kipke et al., 1998) older homeless youth may be more likely to be tested because they are informed of the risks and may be more aware of health service locations. In contrast, younger homeless adolescents, by the very nature of their developmental stage, may be more likely to be risk takers and believe that they are invincible when it comes to experimentation with substance use and sexual activity, and thus have lower concerns regarding potential negative outcomes (Whitbeck \& Hoyt, 1999). As such, these factors may contribute to their lower rates of testing (Goodman \& Berecochea, 1994).

In terms of family background, both physical and sexual abuse were important factors for determining service usage, even after controlling for the influence of all other variables. Both the bivariate and multivariate models demonstrate that physically abused youth have greater odds of using shelter services and street outreach. Many homeless youth tend to leave home after several episodes of physical abuse (Whitbeck \& Hoyt, 1999). If they make a spur of the moment decision to leave, they likely have few available options and thus may be more inclined to use shelter facilities and street outreach. In contrast, non-abused youth may not be dealing with the same time restrictions and thus may have time to make arrangements to stay with relatives and/or friends prior to leaving home. Because abused youth may not be able to return home due to safety concerns, they may wind up using shelter services for an extended time period.

Although sexual abuse was associated with use of food programs, counseling, street outreach, and STI and HIV testing at the bivariate level, other factors reduced its effect to non-significance in the multivariate model. Regardless, those who suffer from sexual abuse have greater odds of being tested for HIV. It is possible that some of these youth have come to the attention of authorities and as such, are administered an HIV test, which may result in their higher level of testing. It is also possible that some youth were fearful that they may have contracted an infection from their abuser and as such, took the initiative to get tested themselves.

Characteristics of the youth's history including being kicked out of their home, spending more nights on the street, and ever staying in a group home were associated with service usage. In the bivariate models, youth who were kicked out were more likely to use shelters, counseling services, and HIV testing. The multivariate models, however, reveal that shelter usage and street outreach were the only significant correlates. One possible explanation is that youth who have been kicked out of their family home, perhaps with little warning, may have limited options and as such, have a need for shelter services. In regard to street outreach, it is possible that youth who have been kicked out tend to spend more time directly on the street and thus garner more experience with being homeless, such as being savvy when it comes to finding food. Subsequently, they have less need for street outreach. In contrast, it is also possible that youth who spend more time sleeping on the street are likely to come into contact with other homeless youth and thus learn survival techniques, including what services are available and which ones to avoid because of rules and expectations.

Both bivariate and multivariate level results show that youth formerly in a group home are more likely to use a variety of services. It is possible that because these youth have previously been in contact with state and public services, they are familiar with both resource availability and the process of accessing services. Additionally, they may have used services such as counseling while in care; therefore, are more likely to take advantage of services in general when they are homeless compared to others who are unfamiliar and less knowledgeable about the system. 


\subsection{Limitations}

These findings have limited generalizability due to the reliance on a convenience sample drawn from one U.S. region. Additional limitations include the use of cross-sectional data and self-reported measures. For practical and ethnical reasons, however, self-reports may be the only feasible means of obtaining sensitive information (Fitzgerald \& Mulford, 1987) especially from homeless persons. Although the reporting of HIV and STI testing and other service usage may have been influenced by recall biases and social desirability, youth were asked about services in two different ways within the survey and their responses were very similar. Furthermore, the present study focused only on whether youth had been tested for STIs and HIV, and it is unlikely that the respondents would forget that they requested or experienced these procedures.

\subsection{Conclusion}

Homeless youth are a diverse group with a high level of service need but providing these services is often difficult. By studying this population in conjunction with their service use patterns, researchers can equip policy makers and service providers with the information they need in order to develop streamlined and successful programs. These findings suggest that numerous homeless and runaway youth take advantage of a variety of services but there is also a sizeable group of young people who do not. Their service usage, to some extent, varies by sex, age, and sexual orientation. A history of physical or sexual abuse is also an important correlate of service usage as well as being kicked out of one's home, spending more nights sleeping on the street, and having a history of staying in a group home. Although there is a paucity of research on general service usage patterns among homeless youth, these findings reveal that there are certain characteristics that need to be considered by service providers when targeting these individuals. It is important to remember that many of these young people have left abusive families and do not trust most adults, with good reason. Because some youth may be cautious of using services, creativity is needed in making services available to all homeless youth. Failure to do so may result in their participation in dangerous and illegal activities to meet their basic needs, as well as negative health outcomes, and potentially long-term homelessness. Furthermore, rule-ridden and bureaucratic programs may not be able to attract and help those most in need.

\subsection{Policy implications}

Public policies related to homelessness, behavioral health, and other social services impact homeless youth. Because service providers have the most access to homeless youth, policies often directly impact or are implemented through these agencies. As a result, knowing which youth are more likely to use certain services will help policy makers understand how to best direct policies so that they will reach the most youth serviced by particular agencies. More importantly, understanding why homeless youth utilize or do not utilize various services can offer considerable help to policy makers and service providers as they ultimately seek to improve the life chances of homeless youth.

Acknowledgment - This research was supported by a grant from the National Institute on Drug Abuse (DA021079). Dr. Kimberly A. Tyler, PI.

\section{References}

Allen, D. M., Lehman, S., Green, T. A., Lindegren, M. L., Onorato, I., \& Forrester, W. (1994). HIV infection among homeless adults and runaway youth, United States, 1989-1992. AIDS, 8, 1593-1598.
Athey, J. L. (1991). HIV infection and homeless adolescents. Child Welfare League of America, 70, 517-528.

Bailey, S. L., Camlin, C. S., \& Ennett, S. T. (1998). Substance use and risky sexual behavior among homeless and runaway youth. Journal of Adolescent Health, 23, 378-388.

Berdahl, T. A., Hoyt, D. R., \& Whitbeck, L. B. (2005). Predictors of first mental health service utilization among homeless and runaway adolescents. Journal of Adolescent Health, 37, 145-154.

Carlson, J. L., Sugano, E., Millstein, S. G., \& Auerswald, C. L. (2006). Service utilization and the life cycle of youth homelessness. Journal of Adolescent Health, 38, 624-627.

Cochran, B. N., Stewart, A. J., Ginzler, J. A., \& Cauce, A. M. (2002). Challenges faced by homeless sexual minorities: Comparison of gay, lesbian, bisexual, and transgender homeless adolescents with their heterosexual counterparts. American Journal of Public Health, 92, 773-777.

Fitzgerald, J. L., \& Mulford, H. A. (1987). Self-report validity issues. Journal of Studies on Alcohol, 48, 207-210.

Geber, G. M. (1997). Barriers to health care for street youth. Journal of Adolescent Health, 21, 287-290.

Goodman, E., \& Berecochea, J. E. (1994). Predictors of HIV testing among runaway and homeless adolescents. Journal of Adolescent Health, 15, 566-572.

Johnson De Rosa, C., Montgomery, S. B., Hyde, J., Iverson, E., \& Kipke, M. D. (2001). HIV risk behavior and HIV testing: A comparison of rates and associated factors among homeless and runaway adolescents in two cities. AIDS Education and Prevention, 13, 131-148.

Johnson De Rosa, C., Montgomery, S. B., Kipke, M. D., Iverson, E., Ma, J. L., \& Unger, J. (1999). Service utilization among homeless and runaway youth in Los Angeles, California: Rates and reasons [Erratum]. Journal of Adolescent Health, 24, 449-458.

Kipke, M. D., Unger, J. B., Palmer, R. F., Iverson, E., \& O'Connor, S. (1998). Association between self-identified peer-group affiliation and HIV risk behaviors among street youth. In J. B. Greenberg, \& M. S. Neumann (Eds.), What we have learned from the AIDS evaluation of street outreach projects (pp. 61-82). Atlanta, GA: Center for Disease Control.

Klein, J. D., Woods, A. H., Wilson, K. M., Prospero, M., Greene, J., \& Ringwalt, C. (2000). Homeless and runaway youths' access to health care. Journal of Adolescent Health, 27, 331-339.

National Runaway Switchboard (2001). Welcome to the National Runaway Switchboard. Online at http://www.nrscrisisline.org/ (Accessed September 30, 2009).

Pergamit, M. E., \& Ernst, M. (2010). Runaway youth's knowledge and access of services. http://www.nrscrisisline.org/media/documents/NORC Final Report 4 22 10.pdf

Rotheram-Borus, M. J., Meyer-Bahlburg, H. F., Koopman, C., Rosario, M., Exner, T. M., Henderson, R., et al. (1992). Lifetime sexual behaviors among runaway males and females. Journal of Sex Research, 29, 15-29.

Solorio, M. R., Milburn, N. G., Andersen, R. M., Trifskin, S., \& Gelberg, L. (2006). Health care service use among vulnerable adolescents. Vulnerable Children and Youth Studies, 1, 205-220.

Solorio, M. R., Milburn, N. G., Andersen, R. M., Trifskin, S., \& Rodrigues, M. A. (2006). Emotional distress and mental health service use among urban homeless adolescents. Journal of Behavioral Health Services and Research, 33, 381-393.

Solorio, M. R., Milburn, N. G., Weiss, R. E., \& Batterham, P. J. (2006). Newly homeless youth STD testing patterns over time. Journal of Adolescent Health, 39(443), e9-e16.

Tyler, K. A., \& Cauce, A. M. (2002). Perpetrators of early physical and sexual abuse among homeless and runaway adolescents. Child Abuse \& Neglect, 26, 1261-1274.

Tyler, K. A., Hoyt, D. R., \& Whitbeck, L. B. (2000). The effects of early sexual abuse on later sexual victimization among female homeless and runaway youth. Journal of Interpersonal Violence, 15, 235-250.

Tyler, K. A., \& Melander, L. A. (2010). The effect of drug and sexual risk behaviors with social network and non-network members on homeless youth's STI and HIV testing. Sexual Health, 7, 434-440.

Tyler, K. A., Whitbeck, L. B., Chen, X., \& Johnson, K. (2007). Sexual health of homeless youth: Prevalence and correlates of sexually transmissible infections. Sexual Health, 4, 57-61.

Whitbeck, L. B., \& Hoyt, D. R. (1999). Nowhere to grow: Homeless and runaway adolescents and their families. New York, NY: Aldine de Gruyter 